\title{
Information Management of Web Application Based Environmental Performance Management in Concentrating Division of PTFI
}

\author{
Arif Susanto ${ }^{1,2, *}$ and Nur Budi Mulyono ${ }^{2}$ \\ ${ }^{1}$ Doctoral Program in Environmental Science, School of Postgraduate Studies, Diponegoro University, Semarang - Indonesia \\ ${ }^{2}$ School of Business and Management, Institut Teknologi Bandung, Bandung - Indonesia
}

\begin{abstract}
The changes of environmental management system standards into the latest version, i.e. ISO 14001:2015, may cause a change on a data and information need in decision making and achieving the objectives in the organization coverage. Information management is the organization's responsibility to ensure that effectiveness and efficiency start from its creating, storing, processing and distribution processes to support operations and effective decision making activity in environmental performance management. The objective of this research was to set up an information management program and to adopt the technology as the supporting component of the program which was done by PTFI Concentrating Division so that it could be in line with the desirable organization objective in environmental management based on ISO 14001:2015 environmental management system standards. Materials and methods used covered technical aspects in information management, i.e. with web-based application development by using usage centered design. The result of this research showed that the use of Single Sign On gave ease to its user to interact further on the use of the environmental management system. Developing a web-based through creating entity relationship diagram (ERD) and information extraction by conducting information extraction which focuses on attributes, keys, determination of constraints. While creating ERD is obtained from relational database scheme from a number of database from environmental performances in Concentrating Division.
\end{abstract}

\section{Introduction}

Change of environmental management system (EMS) standard into the latest version, i.e. ISO 14001:2015 where an organization is given a three-year transition period [1], can also cause a change on the need of data and information in decision making and achieving the objective of that organization scope [2-3]. There is enough evidence that explains that the success level of an organization is determined by how well information is managed, because information is one of the organization resources [4].

Information is some data that has been processed into a meaningful and useful form for receivers and possesses some real values, or is felt and can cause a change in decision making [5-6] and is communicated well and can be in a form of records, documents, data and files that are created and managed by the organization [7].

Information management is gathering and managing information from one or more resources and their distribution to those who deserve them [8]. Information management is a systematic information management that is imaginative and responsible in creating and using it, where this information will give strategic contribution for organization objective achievement and also ensure that groups and individuals have efficient access to and make effective use of required information to perform the task and to develop themselves [10]. Information management is a continuous activity cycle and is strongly related to the identification of information need, acquisition and information creation, information analysis and interpretation, information organization and storage, information access and dissemination, and information use [8].

Information management includes developing and applying information and strategy policy; data creation and management; information processing; storage and transfer; and information use [10]. Technically, information management covers all system and processes such as web content management; document management; record management; digital asset management; learning system management; technical infrastructure used to support information management programs [4]. In management point of view, information management is an organizational, social, cultural and strategic factor that needs to be paid attention to in improving information in organization [8].

Information management is the organization responsibility that needs to be handled and followed from top management for lower level employees to ensure the effectiveness and efficiency of creation, storage, processing and distribution of information to

Corresponding author: arifssnt@yahoo.com 
support operations and decision making activity in an organization [4]. There are five bases of competitive strategy given by information management, including cost leadership, product differentiation, innovation, growth and alliances [5].

Concentrating Division of PT Freeport Indonesia (PTFI) is a process business unit in mine mineral separation [11-12], and in its environmental management, this division has conducted a transition based on EMS ISO 14001:2015 standard. Therefore a change related to information management is needed, especially for environment performance implementation and achieving the objectives stated in the organization. This information management is to give accurate, real time and comprehensive information for effective decision making in environmental management in PTFI Concentrating Division; to give information and records with low cost and to give maximum service to customers; disposing records which are no longer needed in organization.

Furthermore, information management in Concentrating Division has objective for processing, recording information and distributing it to all stakeholders as effective and efficient as possible to ensure that the information value is identified, and used in order that the environmental management objective achievement occur maximally. In managerial function, the definition of information objective is for leadership, information policy development, allocating proper resources, trainings, and evaluating information and providing feedback [8]. Therefore, Concentrating Division has to be responsible for catching, processing, storing, sharing, preserving and conveying information properly and responsibly.

The strategy to support necessary information management program through digital interface will provide high quality services to the users. There is an important issue arises from this research, i.e. the need to arrange information management program and technology adoption as a support for the program components done by PTFI Concentrating Division in order to be in line with organization objective to be achieved in environmental management based on EMS ISO 14001:2015 standard.

\section{Methods}

In this paper, the method used covers technical aspects in the information management of environmental management performance in the framework of implementing environmental management system based on ISO 14001:2015, i.e. by conducting web-based application planning, designing and development with usage centered design.

This web-based application development is assessed and reviewed base on the process business unit in PTFI Concentrating Division that can be used as reference. Meanwhile, limitation and recommendation in implementing this framework is discussed from practical point of view.

\section{Results and discussion}

\subsection{Policy}

Information management evolution category consists of traditional era and technical era. Traditional era covers a period where information is managed manually by using human brain and hands, papers and pens or pencils. Technology era is a period where information technology is introduced into information program management to handle several problems attached in the manual system [13]. Effective information management involves three activities, i.e. planning method, procedure control and organization management. This emphasizes that the function of management, i.e. PlanningOrganizing-Actuating-Controlling (POAC), is very important in every information management program.

There were two important elements in this research; the need for policy and strategy to manage information management program and the adoption of technology as a supporting component of information management program upon the implementation of EMS ISO 14001:2015 in PTFI Concentrating Division.

Similarly with all ISO management system standards, ISO 14001 also covers the need for organization system improvement as well as continuous approach for environmental problems. In EMS ISO 14001:2015, there are key elements related to information management stated in: clause 7.4-Communication (covering 7.4.17.4.3); clause 7.5-Documented Control (7.5.1-7.5.3); clause 8-Operation (covering sub clauses 8.1-8.2); clause 9-Performance Evaluation (covering sub clauses 9.1-9.3); and clause 10-Improvement (clause 10.1-10.2).

The need for policy and strategy to manage information management program upon the implementation of EMS 14001:2015 in PTFI Concentrating Division is the first step stated in environmental policy change. This environmental policy states information management created by the top management to be internalized into the organization where this policy ensures that environment is an integrated part that starts with planning, engineering and operations. This is in line with the function of management, i.e. POAC. The implementation of environmental management system was done sustainably and continuous improvement is done to achieve the goals based on valid and scientific data. Therefore information management is a very necessary element.

The need for technology adoption as a supporting component of information management program upon the implementation of EMS 14001:2015 in PTFI Concentrating Division is achieved by developing information management infrastructure in the form of web based application where environmental data can be processed into accessible information for all organization members internally and externally in PTFI Concentrating Division. 


\subsection{Environmental performance management}

The stage of environmental performance data collection is done with direct observation on the field, interview with stakeholders, and searching for organization data sources to identify environmental aspects which will be Key to Environment Performance Indicator (KEPI), and questionnaire distribution to the people who are competent in production process.

Identifying KEPI by determining performance indicators starts with defining context or organization, listing all interested parties and scope of Environmental Management System. Afterwards, corporate objectives (goals) and environmental targets to achieve, where leadership, which acts as part of management system, shall confirm them through plan-do-check-action cycle, and through review on environmental policy. Then, the environmental aspects from corporate activities are identified to be given weighing based on the criteria of risk and opportunity assessment results.

Evaluation based on these criteria aims to know the environmental aspects of the production process that shall create quite big impacts so they need to be considered as environmental performance indicators. The environmental aspects considered significant as an impact are monitored and controlled so they keep fulfilling the compliances, thus operational control acts as a control in environmental performance achievement.

Environmental performance has a two-side meaning. On one side, it means all the negative effects on the environmental elements, i.e water, ground, air, etc., caused by activities of organization. And the other side, it can be defined as acts and their effects in connection with prevention and decreasing the charging of these elements [14]. Environmental performance evaluation is a management possibility for:

1. decreasing cost and expenditures,

2. increasing the market position and the value of the organization,

3. helping the observation of direction,

4. getting a higher motivation of leaders, managers and staff as well.

Designing Environmental Performance Measurement System uses integration from a model of environmental management system which follows Plan-Do-Check-Act (PDCA) with a concept of IEMPS (Integrated Environment Performance Measurement System). The objective of using IEMPS model is to obtain a structured process to achieve continuous improvement in environmental management, as illustrated in figure 1 below. Environmental performance assessment using IEPMS method shall consider two measures; quantitative and qualitative. Therefore the result obtained shall be more integrated, because it considers relevance, analysis accuracy, measurability and comparability [15]. To conduct KEPI designing, a comprehensive study on identifying organization activity based on life-cycle perspectives is conducted.

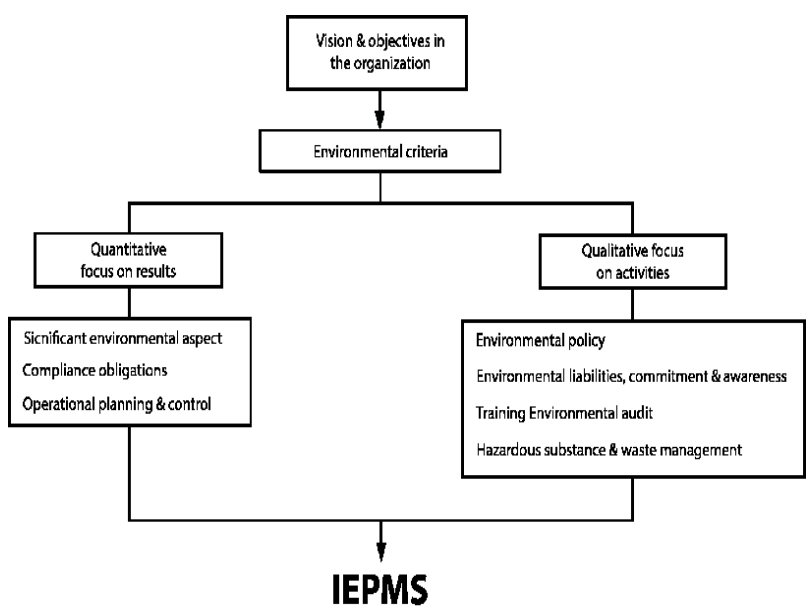

Fig. 1. Integrated Environment Performance Measurement System (IEPMS)

Furthermore, a model of environmental performance measurement [16] is illustrated in figure 2 as follows.

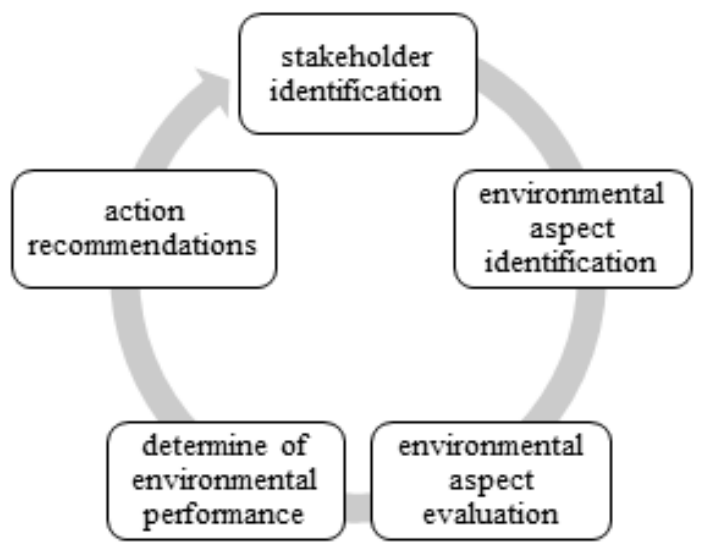

Fig. 2. Model of Environmental Performance Measurement

\subsection{Control of Documented Information and Web Application}

The major change to ISO 14001:2015 means that new standard is opportunity for Concentrating Division PTFI to align a strategic direction with PTFI wide environmental management system, increased focus on improving environmental performance. Mandatory documents required by ISO 14001:2015 depicted in table 1. A mandatory records depicted in table 2 as below.

In implementing environmental performance information management, web applications were used. This application planning aimed for the users to benefit all information on the implementation of environmental management system in Concentrating Division easily, started with access to enter the intranet network system by using usage centered design.

Usage centered design is a systematic process using abstract models to design the smallest, simplest system that fully and directly supports all the tasks users need to accomplish [17]. Its focus on usage (improved tools 
supporting ask accomplishment), driving by models and modelling, selective user involvement, design by modelling, systematic and fully specified process, and design by engineering.

Table 1. Mandatory documents required by ISO 14001:2015 in PTFI Concentrating Division

\begin{tabular}{|l|l|}
\hline \multicolumn{2}{|c|}{ Documents } \\
\hline Clause 4.3 & Scope of the EMS \\
\hline Clause 5.2 & Environmental Policy \\
\hline Clause 6.1.1 & Risk and Opportunities \\
\hline Clause 6.1.2 & $\begin{array}{l}\text { Criteria for evaluation of significant } \\
\text { environmental aspects }\end{array}$ \\
\hline Clause 6.1.2 & Significant environmental aspects \\
\hline Clause 6.2 & $\begin{array}{l}\text { Environmental objectives and plans for } \\
\text { achieving them }\end{array}$ \\
\hline Clause 8.1 & Operational control \\
\hline Clause 8.2 & Emergency preparedness and response \\
\hline
\end{tabular}

Table 2. Mandatory records required by ISO 14001:2015 in PTFI Concentrating Division

\begin{tabular}{|l|l|}
\hline \multicolumn{2}{|c|}{ Records } \\
\hline Clause 6.1.3 & Compliance obligations records \\
\hline Clause 7.2 & $\begin{array}{l}\text { Records of training, skills, experience and } \\
\text { qualifications }\end{array}$ \\
\hline Clause 7.4 & Evidence of communication \\
\hline Clause 9.1.1 & Monitoring and measurement results \\
\hline Clause 9.2 & Internal audit programs \\
\hline Clause 9.2 & Results of internal audits \\
\hline Clause 9.3 & Results of the management review \\
\hline Clause 10.1 & Results of corrective actions \\
\hline
\end{tabular}

Web single sign on (SSO) was used as a technique to authenticate the users, which later on, automatically enter the Concentrating Division EMS as shown in figure 3. SSO could increase the usability of a network as a whole and at the same time to manage the other environmental performance indicators. SSO as operating system login was made by inserting username in the form of 8-digit Universal Identity number of PTFI employees, and with a password of the last 4-digit of the UID number, so the users can enter the environmental web based (figure 4) and manage their environmental performance.

Single Sign-On (SSO) illustrated in figure 3 was used in the adoption of web-based application in ISO 14001:2015 implementation in PTFI Concentrating Division, where network users must do credential authentication with username and password for every services for registered users. Users authenticate once only for login to the system services to be used without further interaction manuals.

The web-based application developed in ISO 14001:2015 implementation uses usage-centered design, where this design focuses on usage (improved tools supporting task accomplishement); driven by model and modeling; selective user involvement; systematic and fully specified process and design by engineering.

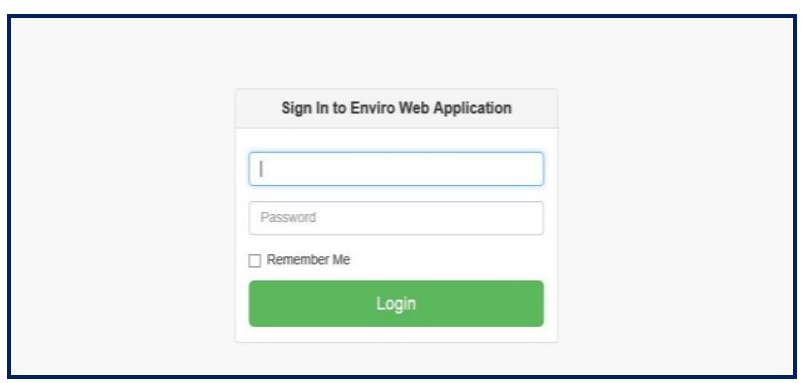

Fig. 3. Web Single Sign On to Environmental Web Application in PTFI Concentrating Division

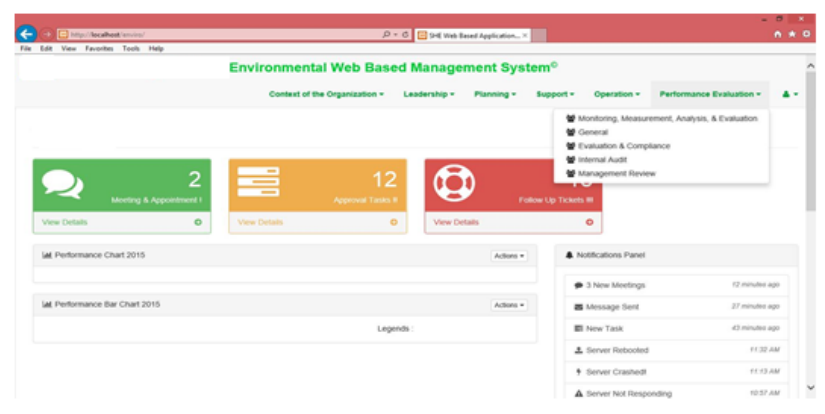

Fig. 4. View of Web Application in the Implementation of EMS in PTFI Concentrating Divis ion

Usage centered web design projects a lightweight form of the process has evolved, takes certain modeling and design shortcuts, when practical, the time to gather, model and validate user requirements is further reduced by developing models collaboratively with end users. Agile usage centered design proceeds [18]:

1. Preliminary steps:

a. Essential purpose and preconception with clarify business and user purposes then fantasize and set aside preconceptions of features, facilities, content and capabilities;

b. Exploratory modelling: identify questions, ambiguities, and areas of risk and uncertainty.

2. First iteration:

a. Role modelling with inventory and prioritize all user roles and select intially targeted subset;

b. Task modelling with inventory and prioritize all tasks and select initially targeted subset;

c. Task clustering with group all tasks by affinity and draft overall navigation architectures;

d. Design draft visual and interaction scheme, review and revise aesthetic design;

e. Abstract prototyping with develop content model for interaction contexts supporting selected subset of tasks;

f. Design and develop detailed user interface design for selected interaction contexts;

g. Construction program designed portions of user interface.

Methods consist of two stages, i.e. developing a webbased through creating entity relationship diagram (ERD) and information extraction (figure 5). The first 
stage is conducting information extraction which focuses on attributes, keys, determination of constraints. While creating ERD is obtained from relational database scheme from a number of database from environmental performances in Concentrating Division.

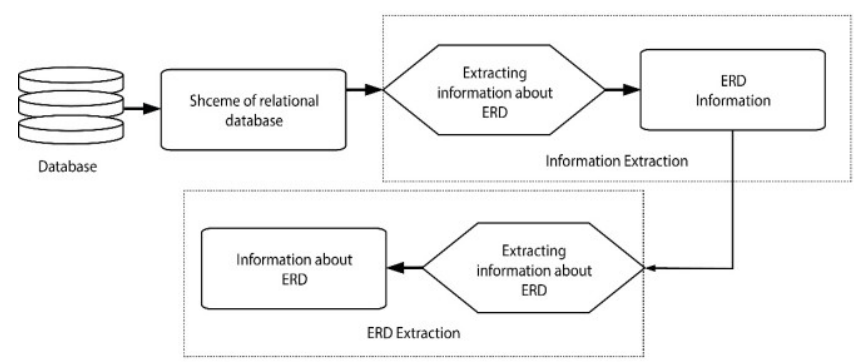

Entity Relationship Diagram (ERD) is a common diagram, which aims to present the database structure in conceptualized form. To build good ERD and excellent schema depends on type of word (verb, noun, adjective, and gerund) [19]. It can be generated from database that make it understandable and simple diagram as depicted for stack emission test (figure 6).

Extracted ERD schema set from an operational relational database [20]. Designers must use tools to reach best implementation of these methodologies by ER-Draw to represent ERD and translated to schema of relational database [21].

Fig. 5. ERD Diagram Database Scheme

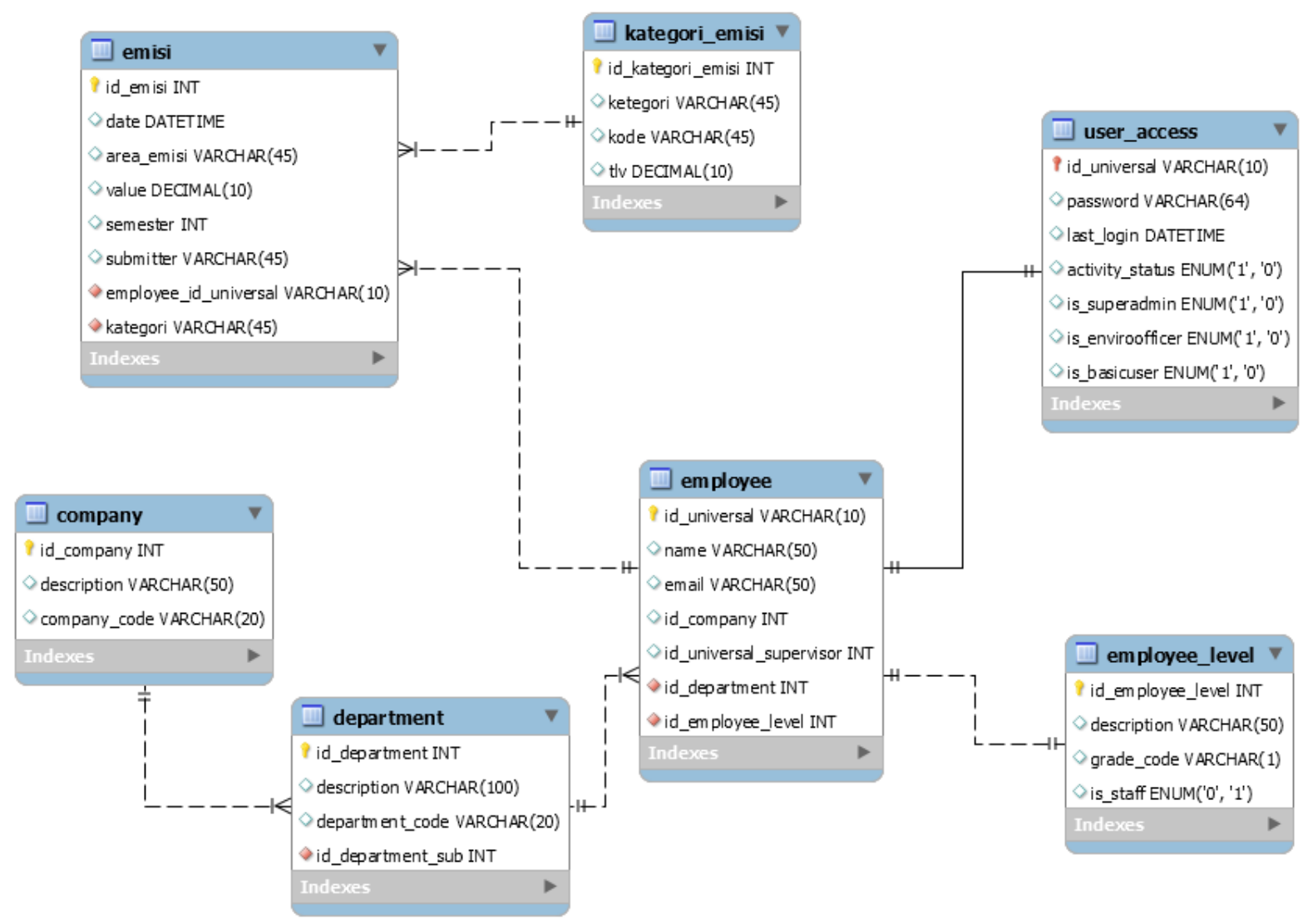

Fig. 6. ERD for Stack Emission Test

The use of web-based application in EMS ISO 14001:2015 starts with information extraction process by using relational database scheme, (sample for stack emission test and its depicted in figure 6) as main input, and depends on the available contextual data, or depends on database script code. In the first sight of the relational database scheme, several information can become clear and on a closer look, some important information can be defined. This information contains database about attributes, entities and relationship between these entities. Figure 6 presents ERD from relational database and validation of the extraction results used by more advanced rules and based on keywords, and depends on the table that contains data or script code of the database. The web application contains the management of compliance obligations records which are obtained from the implementation of the regulations and laws.

\section{References}

1. ISO. Introduction ISO 14001:2015. Ed. 1 (2015).

2. R. Saloojee, D. Groenwald, A.S. du Toit, S Afr J Inf Manag, 6, 62-70 (2007).

3. A. Weintraub, L. Owens, E. Jedinak. Cambridge M.A. USA: Forrester Research, Inc. (2013). 
4. G.S. Reddy, R. Srinivasu, S.R. Rikkula, V.S. Rao. International Journal of Reviews in Computing, 5, 2076-3336 (2009).

5. J.A. O’Brien, and G.M. Marakas. E 14. New York: McGraw-Hill (2008).

6. K.C. Laudon, and Z. Irani. Elsevier: Information \& Management, 227-242, (2004).

7. M.F. Robek, G. F. Brown, and D.O. Stephens. E 4. New York: McGraw-Hill, Columbus (1995).

8. J. Robertson. Step Two Design Pty. Ltd., (2005).

9. S. Henczel. Worldwide Conference on Special Librarianship. Brighton: Special Libraries Association (SLA), 210-226, (2000).

10. E. Maceviciute, and T.D. Wilson. Information Research, 7, (2002).

11. A. Susanto, E.K. Putro, R. N. Wulan, and W.E. Yochu. Globally Harmonized System (GHS) Implementation and Management of Hazardous Substances. 1st International Conference on Sustainable Agriculture and Environmental (ICSAE), Solo: Sebelas Maret University, 302-308 (2012).
12. A. Susanto. Thesis. School of Business and Management, Institut Teknologi Bandung, (2017).

13. M.J. Earl. Mayland Avenue: Prentice Hall International (UK) Ltd., (1989).

14. W.L. Kuhre. Prentice Hall, Inc., (1996).

15. M. Stutz, P. Singhal, M. Terho, S. Ahonen, G. Rice, H. van der Wel. LCA Info, (2004).

16. E. Gunther, and A. Sturm. Technische Universitat Dresden, (2000).

17. L.L. Constantine and L.A.D. Lockwood. MA: Addison-Wesley, (1999).

18. L.L. Constantine and L.A.D. Lockwood. MA: Addison-Wesley, (2001).

19. P.P.S. Chen. Information Sciences, 29, 127-149 (1983).

20. S. Xu, L. Yu and S. Lu. Computers and Their Applications: 143-146, (2003).

21. N. Mfourga, N. Reverse Engineering, Proceeding of the Fourth Working Conference on IEEE, (1997). 